\title{
Ultrasound in Medicine and Biology
}

RUSH: Ultrasound in Medicine and Biology article for proofing (\# 8156)

\section{$====$}

Dear Author,

The proof of your article, to be published by Elsevier in Ultrasound in Medicine and Biology, is available as a "PDF" file at the following URL:

http://rapidproof.cadmus.com/RapidProof/retrieval/index.jsp

Login: your e-mail address

Password: ----

The site contains 1 file. You will need to have Adobe Acrobat Reader software to read these files. This is free software and is available for user download at: http://www.adobe.com/products/acrobat/readstep.html

After accessing the PDF file, please:

1) Carefully proofread the entire article, including any tables, equations, figure legends and references.

2) Ensure that your affiliations and address are correct and complete.

3) Check that any Greek letter, especially "mu", has translated correctly;

4) Verify all scientific notations, drug dosages, and names and locations of manufacturers;

5) Be sure permission has been procured for any reprinted material.

6) Answer all author queries completely. They are listed on the last page of the proof;

You may choose to list the corrections (including the replies to any queries) in an e-mail and return to me using the "reply" button. Using this option, please refer to the line numbers on the proof. If, for any reason, this is not possible, mark the corrections and any other comments (including replies to questions) on a printout of the PDF file and fax this to Lorraine Bernazzani (fax \#: 845-883-5682), or mail to the address given below.

If you submitted usable colour figures with your article they will appear in colour on the web, at no extra charge, as you can see in the attached PDF proof of your article.

Do not attempt to edit the PDF file (including adding post-it type notes).

Within 48 hours, please return the following to the address given below:

1) Corrected PDF set of page proofs

2) Print quality hard copy figures for corrections if necessary (we CANNOT accept figures on disk at this stage). If your article contains color illustrations and you would like to receive proofs of these illustrations, please contact us within 48 hours.

Information on the status of your article can be found via Elsevier's Author Gateway (http://authors.elsevier.com). For access you will need to provide your surname and our reference code (journal acronym and article number: see the 'Subject line' of this e-mail).

If you have any problems or questions, please contact me. PLEASE ALWAYS INCLUDE YOUR ARTICLE NUMBER (8156) WITH ALL CORRESPONDENCE.

Sincerely,

Lorraine Bernazzani

Issue Manager, UMB

236 Patura Road 


\section{Ultrasound in Medicine and Biology}

Modena, NY 12548

Tel: 845-883-5681

Fax: 845-883-5682

Email: lbernazz@optonline.net 


\title{
COMPARABILITY OF ECHOGRAPHIC AND TOMOGRAPHIC ASSESSMENTS OF BODY FAT CHANGES RELATED TO THE HIV ASSOCIATED ADIPOSE REDISTRIBUTION SYNDROME (HARS) IN ANTIRETROVIRAL TREATED PATIENTS
}

\author{
Rosario Gulizia, ${ }^{*}$ Alessandro Vercelli, ${ }^{\dagger}$ Cristina Gervasoni, ${ }^{*}$ Alessia Uglietti, ${ }^{\S}$ \\ Massimiliano Ortu, ${ }^{*}$ Giovanna Ferraioli, ${ }^{*}$ Massimo Galli, ${ }^{\ddagger}$ Carlo Filice* \\ *Division of Infectious and Tropical Diseases, Foundation IRCCS S Matteo, University of Pavia, Pavia, Italy; \\ ${ }^{\dagger}$ Institute of Radiology, Foundation IRCCS S Matteo, University of Pavia, Pavia, Italy; ${ }^{\ddagger}$ Infectious and Tropical \\ Disease Institute, IRCCS L. Sacco, University of Milano, Milano, Italy; and ${ }^{\S}$ Division of Infectious Diseases, \\ Foundation IRCCS S Matteo, University of Pavia, Pavia, Italy
}

(Received 13 September 2007; revised 21 October 2007; in final form 14 December 2007)

\begin{abstract}
To assess the comparability of ultrasonographic (US) subcutaneous fat thickness (SFT) measurements in comparison with computed tomography (CT) at reference points (RPs) representative of HIV related adipose redistribution syndrome (HARS) in patients treated with antiretrovirals. US and CT measurements were compared in nine patients with clinical reports of HARS. We obtained the best resolution of facial (at deepest point of Bichat pad), brachial (in the dorsal face of arm) and crural SFT (at mid thigh) by means of minimal transducer pressures avoiding potential biases such as stand off pads pressure on the skin and artefacts due to too abundant quantity of gel. CT scans were obtained in the same RP where US measurements were performed such as identified by means of metallic skin markers. Median US measurement of facial SFT was $8.8 \mathrm{~mm}(95 \%$ CI: 3.1 to 13.4$), 3.95 \mathrm{~mm}(95 \%$ CI: 2.62 to 5.84$)$ for brachial SFT and $4 \mathrm{~mm}$ (95\% CI: 3.4 to 9.4) for crural SFT. Median CT assessments of facial SFT was $8.7 \mathrm{~mm}$ (95\% CI: 3.5 to 13.5), $4.2 \mathrm{~mm}$ (95\% CI: 2.6 to 5.88 ) for brachial SFT and $5 \mathrm{~mm}(95 \%$ CI: 3.9 to 10.3) for crural SFT, with no significant difference at each RP. A linear regression showed good CT/US comparability at each RP, with no significant deviation from linearity $(p>0.10)$. US shows to be highly comparable with CT, excluding invaliding biases as the transducer pressure on the skin. Given the proven efficacy on the HARS assessments, if well standardized, US could be a reliable method, simpler than CT in the management of body fat changes related to HARS. (E-mail: steinman@imaging.robarts.ca) (C) 2008 World Federation for Ultrasound in Medicine \& Biology.
\end{abstract}

Key Words: Ultrasonography, Lipodystrophy, HIV infection, Antiretrovirals, Body fat changes.

\section{INTRODUCTION}

Abnormal body fat changes (BFCs) and related metabolic alterations are frequently documented in subjects infected with human immunodeficiency virus (HIV) during the treatment with highly active antiretroviral therapies (HAART) (Bogner et al. 2001; Mallon et al. 2003) and are described as HIV associated adipose redistribution syndrome (HARS) (Carr 2003; Carr et al. 1998; Lichtenstein 2005; Lichtenstein et al. 2007).

If the predominant increase of visceral adipose tissue (VAT), lipohypertrophy (LH) and the related meta-

Address correspondence to: Rosario Gulizia, MD, Division of Infectious and Tropical Diseases, IRCCS S. Matteo University of Pavia School of Medicine, Viale Taramelli 5, 27100, Pavia, Italy.E-mail: rosario.gulizia@libero.it bolic alterations lead to the increased cardiovascular risk (Friis-Moller et al. 2003; Grinspoon et al. 2005; Hadigan et al. 2003), the decrease of subcutaneous adipose tissue (SAT), lipoatrophy (LA) is a relevant social problem for its disfiguration and stigmatizing consequences, often so evident as to discourage the adherence to therapy with an increased risk of failure (Gripshover 2003).

The current clinical diagnoses based on subjective perception of patient and objective assessments of clinicians showed considerable risk of misdiagnoses, particularly in the initial and less severe stages.

On the other hand, the too sophisticated elaboration of lipodystrophy score by the Case Definition group study (Carr et al. 2003), the limited availability, the high costs and the risk for ionizing exposure of Dual Energy X-ray absorptiometry (DEXA) (Cavalcanti et al. 2005; 
Yang et al. 2004) and computed tomography (CT) (Engelson et al. 1999; Schambelan 2002; Schwenk 2002; Padilla et al. 2004; Yoshizumi et al. 1999) used to elaborate the score suggest the usefulness of alternative methods.

Ultrasound (US) show advantages that could make it an ideal imaging tool in the assessment of HARS (Martinez et al. 2000; Asensi et al. 2004; Gulizia et al. 2005, 2006; Asensi et al. 2006; Padilla et al. 2007). However, some authors have suggested that it could underestimate the SAT losses because of the transducer pressure on the skin, particularly in patients with facial LA (Carey et al. 2005; Padilla et al. 2007).

The aim of this study was to assess the comparability of US SAT measurements at reference points (RPs) representative of BFCs related to more disabling lipoatrophic findings observed during the HARS in comparison with CT assessments, the current gold standard tool (Padilla et al. 2004; Schambelan 2002; Yoshizumi et al. 1999).

\section{PATIENTS AND METHODS}

Nine adult HIV patients treated with HAART, with no active AIDS-defining illness and documented HARS, were enrolled.

A series of SFT assessments by means of US and CT were performed from our US Unit and the Institute of Radiology of Pavia between the January 2005 and July 2005, as part of a study for which Appropriate Ethics Committee approval was obtained. Informed consent was obtained from each enrolled patient.

Non-obese HIV infected patients were selected as identified by body-mass index (BMI) $<27 \mathrm{~kg} / \mathrm{m}^{2}$, chosen to avoid possible biases as not-lipodystrophic obesity and to select patients with more likelihood to be affected by LA (Muurahainen 1999).

US assessment of fat thickness was always performed by the same physician, an experienced sonologist (GR), blinded to the patient's data, using high-frequency transducers (7.5-13 MHz) of EUB 6500 (HITACHI AQ: 5 Medical Systems) and an Accuvix XQ (Sedas Medical AQ: 6 technologies).

Subcutaneous fat thickness (SFT) has been assessed at three RPs, avoiding any pressure on the underlying skin in the supine position, without any stand-off pad and using minimal quantity of gel to obtain the best resolution of epidermidis and derma included in the SFT measurements.

The US assessments were performed only when a well-defined horizontal hyperechoic line of epidermidis was obtained:

(1) Facial LA was assessed at deepest point of Bichat pad, using a left nasogenian transversal scan SFT from the external line of hyperechoic rim of malar bone to the hyperechoic line of epidermidis (Fig. 1a).

(2) Brachial LA: the assessment of upper limb SFT was performed with a dorsal scans of arm and an anterior flexion of the right elbow joint in a $90^{\circ}$ angle, using a longitudinal scan, $10 \mathrm{~cm}$ above the elbow, from the external rim of superficial fascia of triceps to the hyperechoic line of epidermidis (Fig. 1b).

(3) Crural LA: long scan at $15 \mathrm{~cm}$ above the rotula, from external rim of superficial fascia of right quadriceps to the hyperechoic line of epidermidis (Fig. 1c).

US RPs were identified based on their representation of clinically based BFCs. Three measurements were obtained for each RP; mean value was considered for statistical analysis. CT assessment of SFT was always performed by the same physician blinded to the patient's data using a Somatom Balance, Siemens Medical Solutions.

After a preliminary debate with our radiologists, we choose to obtain CT scans of each RPs identification where the US measurements were performed by means of metallic skin markers (Fig. 2a and b).

\section{Statistical analysis}

Mean and 95\% CI of clinical and demographic data were obtained; moreover, median and 95\% CI of single measurement were assessed.

A t-test and a Mann-Whitney test, respectively, were performed to assess significant statistical differences of clinical and demographic features and all SFT assessments by US and CT. A Passing and Bablok regression was performed to evaluate the comparability of US and CT measurements. Regression equations were obtained with relative intercept A and slope B and their 95\% CI. Null hypothesis was tested at a level of $p$ of 0.05 . Statistical analyses were performed with MEDCALC statistical software (Broekstraat 52 B-9030 Mariakerke, Belgium).

\section{RESULTS}

Study population: mean age in males was 40.8 y (95\% CI: 37.7 to 43.8 ); mean age in females was 41 years (95\% CI: 32.7 to 49.3 ).

Mean BMI in males and females HIV subjects were $20.3 \mathrm{~kg} / \mathrm{m}^{2}$ (95\% CI: 16.8 to 23.8$)$ and $23.6 \mathrm{~kg} / \mathrm{m}^{2}$ (95\% CI: 17.8 to 29.4 ), respectively.

No significant differences were shown between males and females HIV positives. CD4 T lymphocytes titer in HIV infected showed median of 314 cells $/ \mathrm{mmc}$ (95\% CI: 159 to 467$)$ in males and 603 cells/mmc $(95 \%$ CI: 348 to 638 ) in females, respectively.

Mean duration of HIV infection was 13.5 y $(95 \%$ CI: 5.4 to 21.6 ) for males and 12.7 y (95\% CI: 5.1 to 

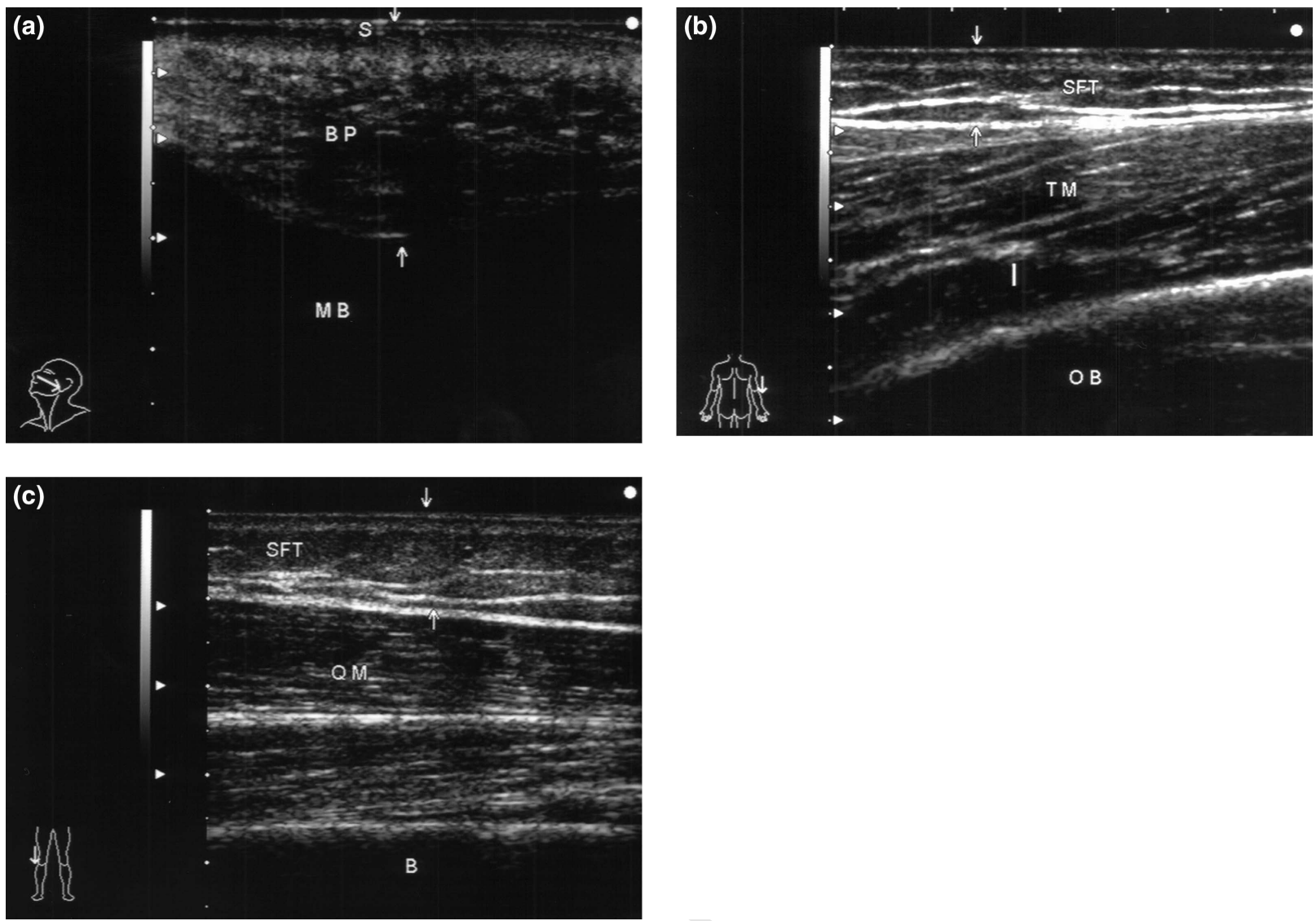

Fig. 1. Sonographic "skin reference points" to measuring cutaneous lipoatrophy. US scan with 7.5 to $13 \mathrm{MHz}$ linear transducers is performed without pressing the underlying skin. (A) Facial reference point: SFT is measured with a left nasogenian transversal scan from the malar bone (MB) to the skin (S) on deepest point of Bichat pad (BP). (B) Upper limb reference point: SFT is measured with a long scans $10 \mathrm{~cm}$ above the right elbow from superficial wall of triceps muscle (T M) upper omeral bone (OB) to the skin. (C) Lower limb reference point: SFT is measured with long scans $15 \mathrm{~cm}$ above the rotula from the superficial wall of quadriceps muscle (QM) upper the femoral bone (B) to the skin.

20.3) for females, whereas mean duration of HAART was 11 years (95\% CI: 9.2 to 12.8$)$ and 9.5 y (95\% CI: 9.5 to 12.8 ) for males and females, respectively. No significant differences were shown based on gender.

All patients were treated with HAART; regimen with 1 PI and 2 NRTIs was administered in four $(44.4 \%)$ patients, two (22.2\%) were treated with regimens PIs and NRTIs free, respectively. Administration of d4T was documented in the pharmacological history of patients in four $(44.4 \%)$ cases.

HARS US findings. Median facial SFT was $8.8 \mathrm{~mm}$ (95\% CI: 3.1 to 13.4 ) with a median upper limb SFT of $3.95 \mathrm{~mm}$ (95\% CI: 2.62 to 5.84) and a median lower limb SFT of $4 \mathrm{~mm}$ (95\% CI: 3.4 to 9.4$)$.

HARS CT findings. Median facial SFT was $8.7 \mathrm{~mm}$ (95\% CI: 3.5 to 13.5 ) with a median upper limb SFT of $4.2 \mathrm{~mm}$ (95\% CI: 2.6 to 5.88) and a median lower limb SFT of $5 \mathrm{~mm}$ (95\% CI: 3.9 to 10.3 ).
The comparison of CT and US SFT measurements showed no statistically significant differences for each RP. Features of enrolled patients are described in Table 1.

As summarized in Fig. 3a, b and c, a Passing and Bablok regression showed good CT/US comparability at each RP, with no significant deviation from linearity ( $p$ $>0.10)$ :

Facial SFT- regression equation: $\mathrm{y}=-0.45(95 \%$ CI -0.27 to 1.46$)+0.99 \times(95 \%$ CI -0.86 to 1.07$)$. Brachial SFT- regression equation: $\mathrm{y}=0.07$ (95\% CI -0.82 to 0.67$)+1.04 \times(95 \% \mathrm{CI}-0.89$ to 1.3$)$. Crural SFT- regression equation: $\mathrm{y}=-0.66(95 \% \mathrm{CI}-0.56$ to $0.93)+0.98 \times(95 \%$ CI 0.91 to 1.2$)$.

\section{DISCUSSION}

HARS is a multifactorial syndrome in which several findings could be described separately or concurrently from generalized (central obesity) or focused LH (dor-
108

109

110

111

112

113

114

115

116

117

118

119

120

121

122

123

124

125

126

127

128

129

130

131

132

133

134

135

136

137

138

139

140

141

142

143

144

T1 145

F3 146

147

148

149

150

151

152

153

154

155

156

157

158

159

160

161 

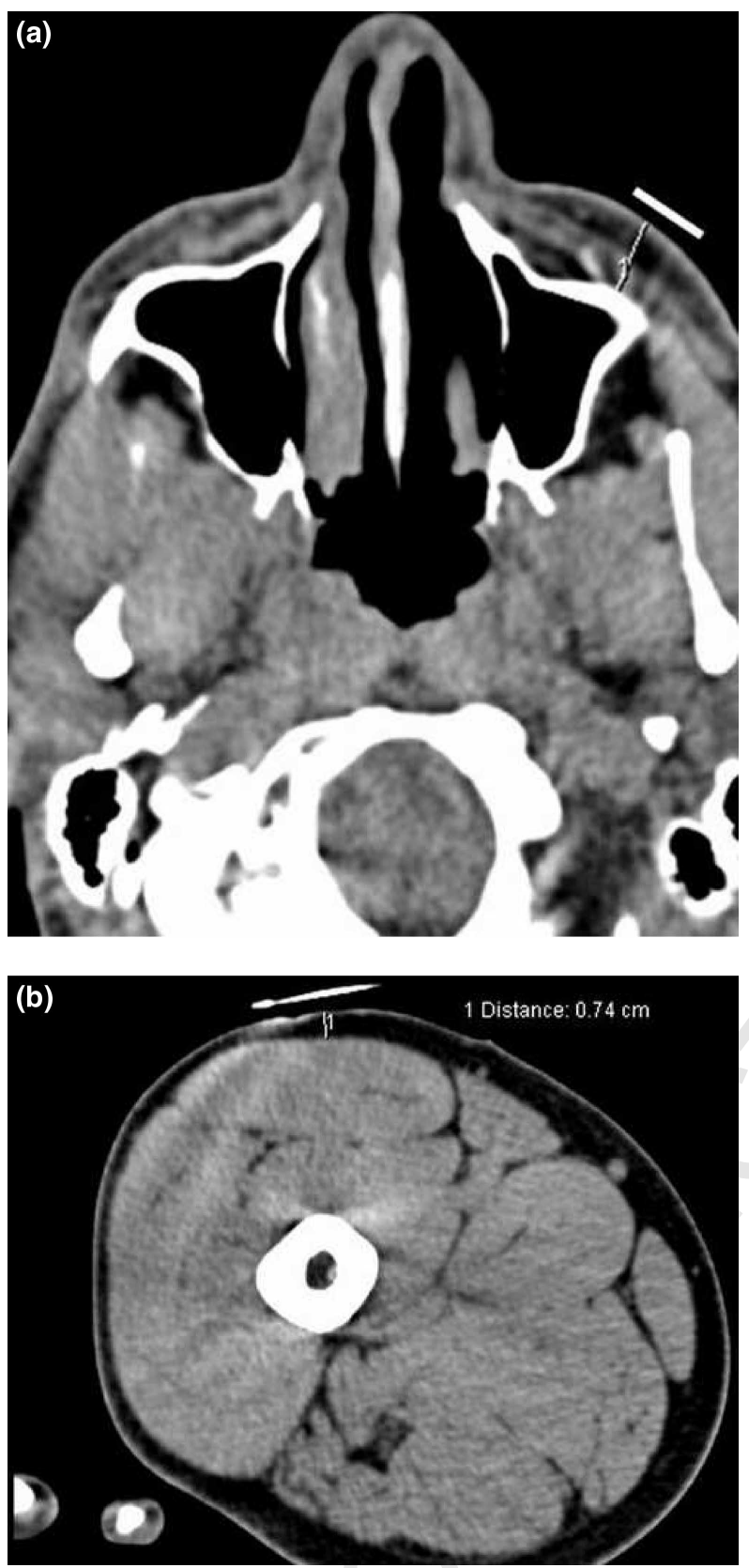

Fig. 2. Tomographic measurements of marked facial (A) and lower limb (B) SFT at reference points corresponding to skin areas where sonographic assessments were performed.

socervical lipomatosis, gynecomastia) to the predominant or mixed LA with facial, brachial and/or crural or buttock LA. The same stigmatizing SFT losses could be generalized or focused (Gripshover 2003; Lichtenstein 2005; Lichtenstein et al. 2007); the diagnosis of BFCs requires, therefore, imaging tools able to assess every body area.

The lack of ionizing radiations, low cost, availability, simplicity and being acceptable to patients suggest that US could be a more practical method than CT and DEXA and an ideal tool, especially in the early identification of HARS.

US accuracy in the assessment of HARS has been demonstrated by several authors, including our group (Martinez et al. 2000; Asensi et al. 2004; Gulizia et al. 2005, 2006; Padilla et al. 2007). Moreover, our and other observations (Martinez et al. 2000) documented good interobserver reliability, little intraobserver variability (less than 5\%) and a good correlation with the HARS grading scale (Asensi et al. 2006).

In our opinion, however, the good perspectives of US require the standardization of measurement techniques and the identification of common RPs acknowledged from all authors.

Several BFCs are described in the HARS, and obviously more potential RPs have been studied, also by means of CT and US comparisons (Padilla et al. 2007), such as the omental fat thickness or perirenal fat diameter for the assessment of lipohypertrophic findings of HARS (Martinez et al. 2000; Asensi et al. 2004, 2006; Gulizia et al. 2005, 2006). On the other hand, if cervical lipomatosis had been well studied by means of US (Piliero et al. 2003; Palacios et al. 2007), it would be a less common type of fat redistribution in this population.

In the current study, we focused our attention on the more representative and disabling damages described in the daily practice. Based on clinically different presentations of LA, we identified three RPs representative of facial, brachial and crural LA.

Lastly, because the US anatomy of SFT is comparable at each body area, good comparability between US and CT in the assessment of SFT observed at chosen RPs

Table 1. Demographic, clinical, echographic and tomographic features of series for HIV lipoatrophic patients

\begin{tabular}{|c|c|c|}
\hline Features & \multicolumn{2}{|c|}{ Mean $(95 \% \mathrm{CI})$} \\
\hline \multicolumn{3}{|l|}{ Male } \\
\hline No. patients & \multicolumn{2}{|c|}{4} \\
\hline Age, y & \multicolumn{2}{|c|}{$40.8(37.7-43.8)$} \\
\hline BMI, $\mathrm{kg} / \mathrm{m}^{2}$ & \multicolumn{2}{|c|}{$20.3(16.8-23.8)$} \\
\hline Duration of HIV, y & \multicolumn{2}{|c|}{$13.5(5.4-21.6)$} \\
\hline Duration HAART, y & \multicolumn{2}{|c|}{$11(9.2-12.8)$} \\
\hline $\mathrm{CD} 4$, cells $/ \mathrm{mmc}$ & \multicolumn{2}{|c|}{$314(159-467)$} \\
\hline \multicolumn{3}{|l|}{ Female } \\
\hline No. patients & \multicolumn{2}{|c|}{5} \\
\hline Age, y & \multicolumn{2}{|c|}{$41(32.7-49.3)$} \\
\hline BMI, $\mathrm{kg} / \mathrm{m}^{2}$ & \multicolumn{2}{|c|}{$23.6(17.8-29.4)$} \\
\hline Duration of HIV, $y$ & \multicolumn{2}{|c|}{$12.7(5.1-20.3)$} \\
\hline Duration HAART, y & \multicolumn{2}{|c|}{$9.5(9.5-12.8)$} \\
\hline $\mathrm{CD} 4$, cells/mmc & \multicolumn{2}{|c|}{$603(348-638)$} \\
\hline & US & CT \\
\hline SFT, mm & Median $(95 \% \mathrm{CI})$ & Median $(95 \% \mathrm{CI})$ \\
\hline Facial & $8.8(3.1-13.4)$ & $8.7(3.5-13.5)$ \\
\hline Brachial & $3.95(2.62-5.84)$ & $4.2(2.6-5.88)$ \\
\hline Crural & $4(3.4-9.4)$ & $5(3.9-10.3)$ \\
\hline
\end{tabular}


(a)

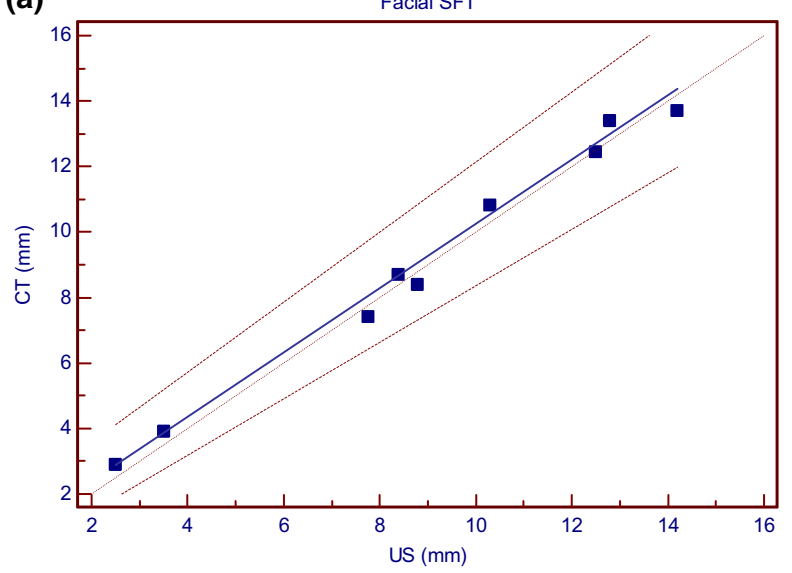

(c)

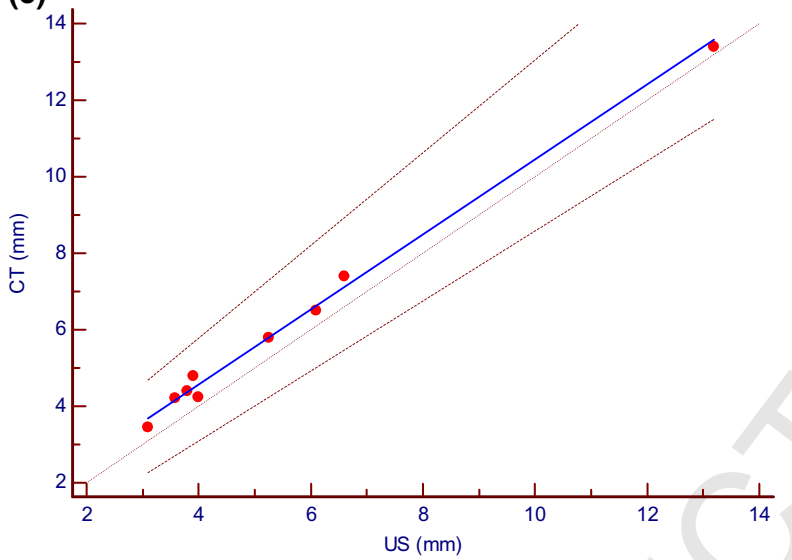

(b)

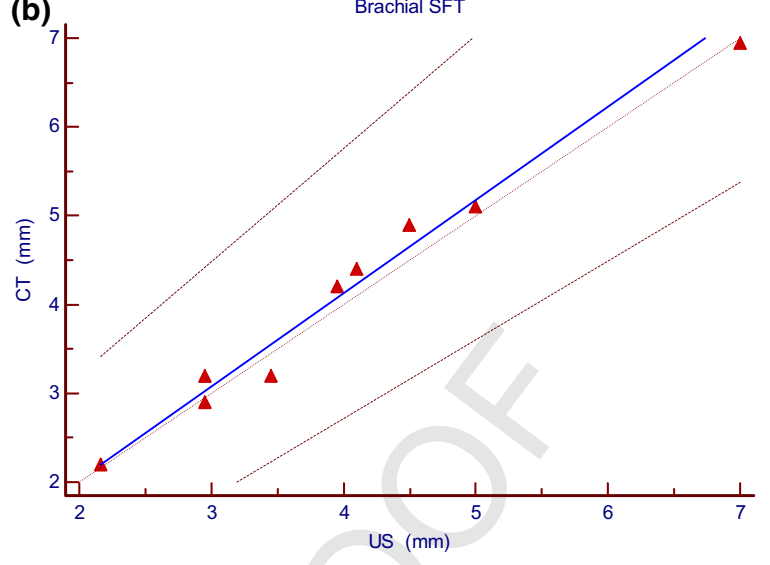

216

217

218

219

220

221

222

223

224

225

226

227

228

229

230

231

232

233

234

235

236

237

238

239

240

241

242

243

244

245

246

247

248

249

250

251

252

253

254

255

256

257

258

259

260

261

262

263

264

265

266

267

268

269 the careful identification and measurement of RPs to avoiding any potential bias such as the pressure offered by stand-off pads in the skin and taking care to exclude

The good comparability between the CT and US measurements excludes any relevance of the US transducers pressure on the underlying skin and confirms the rex 
artefacts due to a too abundant quantity of gel to obtaining the best resolution of SFT, such as we have proposed, with minimal transducer pressure.

Although the limited number of enrolled patients suggests wariness in our conclusions, Milinkovic et al. (2003) and other authors (Padilla et al. 2007) reported a good correlation between US and CT SFT measurements and, if confirmed by larger studies, it could enforce the good perspectives of US to obtain reliable assessments of BFCs related to LA in HIV patients treated with antiretrovirals.

\section{REFERENCES}

Asensi V, Martin-Roces E, Carton JA, Collazos J, Maradona JA, Alonso A, Medina M, Aburto JM, Martinez E, Rojo C, Bustillo E, Fernandez C, Arribas JM. Perirenal fat diameter measured by echography could be an early predictor of lipodystrophy in HIV type 1-infected patients receiving highly active antiretroviral therapy. Clin Infect Dis 2004;39:240-247.

Asensi V, Martin-Roces E, Collazos J, Carton JA, Maradona JA, Alonso A, Medina M, Aburto JM, Fernandez C, Martinez E. Association between physical and echographic fat thickness assessments and a lipodystrophy grading scale in lipodystrophic HIV patients: Practical implications. AIDS research and human retroviruses. 2006;22:830-836.

Bogner JR, Vielhauer V, Beckmann RA, Michl G, Wille L, Salzberger B, Goebel FD. Stavudine versus zidovudine and the development of lipodystrophy. J Acquir Immune Defic Syndr 2001;27:237-244.

Carey D, Wand H, Martin A, Rothwell S, Emery S, Cooper DA, Carr A. Evaluation of ultrasound for assessing facial lipoatrophy in a randomized, placebo-controlled trial. Aids 2005;19:1325-1327.

Carr A. HIV lipodystrophy: Risk factors, pathogenesis, diagnosis and management. Aids 2003;17(Suppl. 1):S141-148.

Carr A, Law M. An objective lipodystrophy severity grading scale derived from the lipodystrophy case definition score. J Acquir Immune Defic Syndr 2003;33:571-576.

Carr A, Samaras K, Burton S, Law M, Freund J, Chisholm DJ, Cooper DA. A syndrome of peripheral lipodystrophy, hyperlipidaemia and insulin resistance in patients receiving HIV protease inhibitors. Aids 1998;12:F51-F58.

Cavalcanti RB, Cheung AM, Raboud J, Walmsley S. Reproducibility of DXA estimations of body fat in HIV lipodystrophy: Implications for clinical research. J Clin Densitom 2005;8:293-297.

Engelson ES, Kotler DP, Tan Y, Agin D, Wang J, Pierson RN, Jr., Heymsfield SB. Fat distribution in HIV-infected patients reporting truncal enlargement quantified by whole-body magnetic resonance imaging. Am J Clin Nutr 1999;69:1162-1169.

Friis-Moller N, Weber R, Reiss P, Thiebaut R, Kirk O, d'Arminio Monforte A, Pradier C, Morfeldt L, Mateu S, Law M, El-Sadr W, De Wit S, Sabin CA, Phillips AN, Lundgren JD. Cardiovascular disease risk factors in HIV patients-association with antiretroviral therapy. Results from the DAD study. Aids 2003;17:1179-1193.

Gellett LR, Haddon L, Maskell GF. CT appearances of HIV-related lipodystrophy syndrome. Br J Radiol 2001;74:382-383.

Grinspoon S, Carr A. Cardiovascular risk and body-fat abnormalities in HIV-infected adults. N Engl J Med 2005;352:48-62.

Gripshover B, Tien PC, Saag M. Fat Redistribution and Metabolic Change in HIV Infection (FRAM) Study investigators. Lipoatrophy is the dominant feature of the lipodystrophy syndrome in HIV- infected men. Proceedings of the Tenth Conference on Retroviruses and Opportunistic Infections. Boston, MA, 2003.>

Gulizia R, Brunetti E, Gervasoni C, Galli M, Filice C. Sonographic assessment of lipodystrophy in HIV-infected patients: Some open questions. Clin Infect Dis 2005;40:323-324; author reply 24-25.

Gulizia R, Vercelli A, Gervasoni C, Ortu M, Calliada F, Troia G, Galli M, Filice C. Controversy concerning role of ultrasonographic lipoatrophy assessments in HIV patients. Aids 2006;20:789-790.

Hadigan C, Meigs JB, Wilson PW, D'Agostino RB, Davis B, Basgoz N, Sax PE, Grinspoon S. Prediction of coronary heart disease risk in HIV-infected patients with fat redistribution. Clin Infect Dis 2003;36:909-916.

Lichtenstein K, Balasubramanyam A, Sekhar R, Freedland E. HIVassociated adipose redistribution syndrome (HARS): Definition, epidemiology and clinical impact. AIDS Res Ther 2007:4:16.

Lichtenstein KA. Redefining lipodystrophy syndrome: Risks and impact on clinical decision making. J Acquir Immune Defic Syndr 2005;39:395-400

Mallon PW, Miller J, Cooper DA, Carr A. Prospective evaluation of the effects of antiretroviral therapy on body composition in HIV-1infected men starting therapy. Aids 2003;17:971-979.

Martinez E, Bianchi L, Garcia-Viejo MA, Bru C, Gatell JM. Sonographic assessment of regional fat in HIV-1-infected people. Lancet 2000;356:1412-1413.

Milinkovic A, Vidal S, Bianchi L, Ayuso C, Domingo P, Gomila M, Gatell JM, Martinez E. Comparative assessment of objective methods for the measurement of body fat. Proceedings of the Fifth International Workshop on Adverse Drug Reactions and Lipodystrophy in HIV. Paris: Antiviral Therapy, 2003:L63.

Muurahainen N, Pettit R, Kotler D, Falutz J, Santos G, Kleintop M, Glesby M. Abnormalities in HIV-associated lipodystrophy syndrome that vary by weight status. Proceedings of the First International Workshop on Adverse Drug Reactions and Lipodystrophy in HIV. 53 edn. San Diego, CA, 1999.

Padilla S, Gallego JA, Masia M, Ardoy F, Hernandez I, Gutierrez F. Ultrasonography and anthropometry for measuring regional body fat in HIV-infected patients. Current HIV Res 2007;5:459-466.

Padilla S, Gallego JA, Masia M, Gutierrez F. Single-slice computed tomography and anthropometric skinfold analysis for evaluation of facial lipoatrophy in HIV-infected patients. Clin Infect Dis 2004; 39:1848-1851.

Palacios R, Galindo MJ, Arranz JA, Lozano F, Estrada V, Rivero A, Morales D, Asensi V, del Arco A, Munoz A, Santos J. Cervical lipomatosis in HIV-infected patients: A case-control study. HIV Med 2007;8:17-21.

Piliero PJ, Hubbard M, King J, Faragon JJ. Use of ultrasonographyassisted liposuction for the treatment of human immunodeficiency virus-associated enlargement of the dorsocervical fat pad. Clin Infect Dis 2003;37:1374-1377.

Schambelan M, Benson CA, Carr A, Benson C, Carr A, Currier JS, Dube MP, Gerber JG, Grinspoon SK, Grunfeld C, Kotler DP, Mulligan K, Powderly WG, Saag MS. Management of metabolic complications associated with antiretroviral therapy for HIV-1 infection: Recommendations of an International AIDS Society-USA panel. J Acquir Immune Defic Syndr 2002;31:257-275.

Schwenk A. Methods of assessing body shape and composition in HIV-associated lipodystrophy. Curr Opin Infect Dis 2002;15:9-16.

Yang Y, Zhu WD, Paton NI. Comparison of dual-energy X-ray absorptiometry machines for measuring fat distribution changes of HIV-associated lipodystrophy. Antivir Ther 2004;9:771-778.

Yoshizumi T, Nakamura T, Yamane M, Islam AH, Menju M, Yamasaki K, Arai T, Kotani K, Funahashi T, Yamashita S, Matsuzawa Y. Abdominal fat: Standardized technique for measurement at CT. Radiology 1999;211:283-286.
270 


\section{AUTHOR QUERIES}

\section{AUTHOR PLEASE ANSWER ALL QUERIES}

AQ1- Included first names.

AQ2- Please verify affiliation for Giovanna Ferraioli and Carlo Filice. Are they both affiliated with the Division of Infectious and Tropical Diseases, University of Pavia?

AQ3 - Word edit: "disfiguration" (instead of "disfigurating") OK?.

AQ4 - Spelling edit: "absorptiometry" (instead of "absorbimetry") OK?

AQ5 - Please provide city/state (if located in the USA) or city/country (if located outside the USA) for Hitachi Medical Systems.

AQ6 - Please provide city/country for Sedas Medical technologies.

AQ7- Word edit: "representation" (instead of "representativity") OK?

AQ8 - Please provide city/state or city/country for Siemens Medical.

AQ9 - Word edit: "body area" (instead of "body district") OK?

AQ10- Edit OK? The meaning is not clear.

AQ11- Word edit: "structure" (instead of "anatomy") OK?

AQ12- What is meant by "invaliding"? Do you mean "invalidating"?

AQ13 - What is meant by "alternatively" in this context? Do you want to say "instead of"?

AQ14- Are these proceedings of a meeting? Please provide publisher, editor, and page numbers.

AQ15- Are these proceedings of a meeting? Please provide publisher, editor, and page numbers.

AQ16- Are these proceedings of a meeting? Please provide publisher, editor, and page numbers. 